\title{
Positive and negative impacts of COVID-19, an analysis with special reference to challenges on the supply chain in South Asian countries
}

\author{
K. Karunathilake ${ }^{1,2}$ (D) \\ Published online: 2 September 2020 \\ (c) Institute for Social and Economic Change 2020
}

\begin{abstract}
The Coronavirus or COVID-19 is a disease based on an unknown virus. It seems that it started in China and has widely spread in almost all countries in the world. This pandemic situation is one of the widely spread diseases in recent history. However, there was an influenza pandemic in 1918 with the exact number of deaths still unknown. Some believe that the death toll would have been about 50-100 million people. At the time of writing this article, COVID-19 has infected 5,306,928 persons worldwide (when the article was finalised for publication, the number has increased up to $15,947,291$ ). The article is aimed at analysing the positive and negative impacts of COVID-19 in a sociological perspective. It is further focused on possible challenges to the supply chain in South Asia. South Asian countries are highly influenced by the pandemic situation, and the regional representation is about $4 \%$ in the later part of May 2020 with an increasing tendency. Also, the article has a proposal for the control of the disease as well as the entire socio-economic, environmental and political atmosphere in a country, whilst particularly giving more weight to South Asia. The proposed actions are analysed in short-term, mid-term and long-term basis, and any expert and social worker who is involved in the pandemic control process can gain an insight into what to do and how to perform their tasks. A sociological analysis on COVID19 is very important because there is a wing comprising dominant medical experts in the control and management of the disease. The article emphasises the importance of a sociological analysis in a pandemic situation. Naturally, anyone would think of a pandemic situation in very negative terms due to its emotional, socio-economic, environmental, political and cultural factors. However, it is also positive due to certain factors that help to reintegrate and reorganise the social system as a whole.
\end{abstract}

Keywords Control and management · COVID-19 $\cdot$ Positive and negative impacts · Social domains $\cdot$ Social impacts $\cdot$ Supply chain $\cdot$ Sri Lanka and South Asia

K. Karunathilake

kkarunathilake@gmail.com

1 Department of Sociology, University of Kelaniya, Kelaniya, Sri Lanka

2 Centre for Study Social Systems, School of Social Sciences, Jawaharlal Nehru University, New Delhi, India 
The main objective of this paper is to discuss the positive and negative impacts of COVID19 in a sociological perspective with special attention to the supply change in South Asian countries. In addition, the paper proposes a future action plan or COVID-19 recovery action plan for Sri Lanka as a South Asian country. The country is in a COVID19 affected stage and is gradually progressing into a non-affected stage, and this action plan is focused on at least a five-year period.

There is no argument that the local economic and social spheres as well as global spheres have been challenged and some sectors have been drastically dismantled (Malpass 2020). Therefore, we need to repose our trust mostly on local spheres which facilitate our basic needs and other socio-economic needs structure. As we know very well, we are in possession of a substantial service sector, rather than industrial and agricultural sectors. In contrast to these sectors, we need to maintain sound industrial and agricultural sectors to maintain a good service sector. However, our industrial sector will be severely damaged due to COVID-19. Especially, the apparel and textile industry will be heavily damaged due to COVID-19, since the pandemic has severely affected giant countries such as the USA and European countries. This will lead to lesser and lesser demand for readymade apparels, thus leading to the closure of many apparel industries in the country. The factories would not be able to overcome this situation since their buyers would cut down all possible avenues to recover from the dire situation. The export volumes of the agricultural and fisheries sectors would decrease, creating negative economic and social impacts on Sri Lanka. Though the World Bank issued a statement on March 30, 2020, it does not provide any forecasts on Sri Lanka or South Asian countries. It focuses only on East Asian and Pacific countries whilst highlighting the poverty incident that would increase dramatically (World Bank 2020c). If the economic situation were to deteriorate further and the lower-case scenario prevails, then poverty is estimated to increase by about 11 million people in these regions. In April 2020, the World Bank illustrates the South Asian context of COVID-19 and its impacts. It says that the impact of the pandemic will hit hard low-income people, especially informal workers in the hospitality, retail trade and transport sectors who have limited or no access to healthcare or social safety nets (World Bank 2020a). Furthermore, it focuses that the Sri Lankan economic growth in the first quarter of 2020 is between 3.0 and -0.5 and it will remain low throughout the year. It may slowly grow until 2022 with a $2.5 \%$ growth rate. The forecast analysis shows that Sri Lanka will struggle with the economy. Thus, the country needs a well-integrated plan to avoid economic hardships as well as social and political tensions. Especially, it needs political stability, high level of mass participation in all sectors, attitude change in domestic production and use, and low level of dependency on foreign aids and foreign goods and services. Especially, it will help to refurbish the domestic supply chain as the countries' primary target.

When the Sri Lankan scenario is looked at, the economic growth has translated into shared prosperity with the national poverty headcount ratio declining from $15.3 \%$ in 2006/07 to $4.1 \%$ in 2016 (World Bank 2020b). Extreme poverty is rare and concentrated within some geographical pockets; however, a relatively large share of the population subsists on slightly more than the poverty line. However, COVID-19 would increase poverty incidents to some extent since many apparel sector workers are unemployed or underemployed. Foreign migrant labourers are affected due to the situations in their respective countries and they are losing their decent income. Simultaneously, the tourism and hotel industry will be severely affected, sometimes temporarily as Sri Lanka is managing the pandemic situation satisfactorily and this could attract future foreign tourists on the lookout for healthy living. If the Government of Sri Lanka (GOSL) plans a well-integrated domestic production, strengthening and improvement activities, it will ensure the flow of the 
national supply chain without any disturbances, and also such a situation may help to gain significant improvements in local and foreign tourism.

Within the socio-economic background highlighted above, Sri Lanka needs to have a very comprehensive future action plan to overcome all negative impacts. Especially, it is important to identify the short-term, medium-term, and long-term negative and positive impacts in terms of developing a future action plan or COVID-19 recovery action plan.

When focusing on positive impacts the immediate question that may arise is, what are the positive impacts in a global pandemic situation? Sociologically, there is a theoretical perspective and a method called functionalism or functional perspective and this method could be utilised in analysing the impact of social action (Parsons 1951a, b; Rocher 1972; Luhmann 1995; Knudsen 2010). COVID-19 is a social action, and it can also be considered a great social problem on the basis of Richard Puller's definition. When looked at generally, COVID-19 is a disease spreading through close human contacts in day-to-day social relationships. It is a virus and certain sections also consider this to be a man-made virus or biological weapon. There is no conclusive evidence on who made it or for what purpose. The majority of those directly affected are the elderly and a considerable number of people are dying. The percentage is changing from country to country, and the USA which is highly affected shows that $2.9 \%$ of the deaths are amongst these affected persons. The death toll is very high in Italy which is $13 \%$. In Sri Lanka, it is 3.7\% and it is a higher figure when compared to India, which is $2.8 \%$ (https://www.worldometers.info/coronaviru s/\#countries, 2020). Thus, it is important to understand what the positive impacts are. They are given in the following:

1. People are adapting to a pandemic situation, and they also understand what the ideal social behaviour is in a similar situation. This may include government pandemic management systems and policies.

2. They learnt about social distancing and its rules, conditions and procedures. Especially, how painful it is but useful within the family and the community. Also, they adapt themselves to the situation whilst contemplating the difference between a normal situation and a pandemic situation.

3. As a result of social integration, families and communities engage in a high level of social cohesion or social conscience to face the difficult situation. Hence, everyone is getting used to a common lifestyle, sharing and caring for others, especially the elderly people.

4. The death of an elderly or chronically ill person results in a reorganisation or reunion of the family unit. Though it is not an easy task to bear the psycho-social factors, finally they come to certain common conclusions.

5. Similarly, the government and regional organisations in the global context may reunite to face the pandemic situation. For example, the SARRC countries reunited over COVID-19 and set up financial allocations for supporting poorer nations. The recent SAARC video conference on COVID 19 has resulted in the establishment of a fund for regional cooperation to combat the pandemic. The giant country India contributed USD 10 million followed by Sri Lanka which contributed USD 5 to the fund. This fund can be utilised for the improvement of domestic and regional production whilst aiming at an uninterrupted supply chain in the agricultural, industrial and service sectors.

6. Medical systems in any country will be improved to sustainable levels to face a pandemic situation. They will understand the existing gaps in these systems. Especially, many South and East Asian countries will focus on their indigenous medical systems 
and how it should be integrated with the biomedical system which shows poorer results. Their dominant authority may be challenged by indigenous medical practitioners due to the strength of the indigenous medical systems to treat COVID-19 patients.

7. The global hegemonic power would change and a new hegemonic power relation is taking its place without any brutal war conditions and much economic and social costs. It seems that the USA may lose the hegemonic power, which would be replaced by China and within such a scenario China could achieve its long-term goals. However, it can be delayed and disturbed by the USA through certain economic restrictions against China. Recently, the USA announced that they are willing to withdraw their investments in China. Under such circumstances South Asian countries, particularly India can offer much better economic policies to attract US investments in India. Similarly, Sri Lanka and Bangladesh can grab some such opportunities in certain industrial fields. This may help in improving supply chain values and efficiency in South Asian countries.

8. The new hegemonic power may extend its supporting hands to the developing nations and poorer countries. Thus, there will be a competition amongst China, USA and India to support regional countries in South East Asia. The new world order may be a novel experience to the countries and their people. At the beginning it will be optimistic as per the conflict theory in sociology. If it suits the supply chain system in these countries then the people may accept the new order.

9. There will be many discoveries and innovations in all affected sectors or spheres at national, regional and global contexts. Most of these would be medical, environment, industry and socio-cultural related. These discoveries and innovations will help to manage the supply chain in South Asian countries.

10. The potentials would be in domestic production and services to maintain local traditional lifestyles rather than adapting to modernity. People may repose their trust in many local-level trades and business firms rather than depending on the supermarket systems. These trends strengthen the supply chain network at national and regional levels. Perhaps, there may be some new trading opportunities too amongst regional countries.

11. Domestic production could increase due to family or cottage level agricultural practices including other small-scale handicraft productions in society. This may reduce the market demand to some extent and it may also cause negative effects amongst international trades.

12. As mentioned above, the pandemic situation may increase the level of innovations amongst the people. Some creative-minded people may introduce much effective and productive primary and secondary things, efficient ways and means of productions, low-cost productions, technological advancements, etc. These trends too may strengthen the supply chain network at national and regional levels.

13. People may be attracted to traditional foods and consumption practices mainly based on the human family. Intergenerational social integrity will strengthen and be consolidated by youths. There will be a lesser demand for restaurants and hotel sector supply chains in each level such as national, regional and global due to the social and physical distancing.

14. Decline in defence expenditure at national and global levels and minimising the need or requirements in the arms race, especially in nuclear weaponry systems, at least on a temporary basis. Thus, war fear could be minimised in certain regions. This may in turn influence international terrorism and its supply chain networks.

15. New ideological constructions in many critical subject disciplines, such as medicine, economics, political science, sociology, psychology, robotic sciences, religious and 
humanistic sciences. Hence, research and development activities will expand in every country.

16. Developments in sociological tool-kits and social engineering skills to deliver efficient services through supply chain networks and management of patients and general public.

17. People getting used to do some optional analysis and adapt to follow optimum use of resources, economising resources, and sustainable approaches to satisfy their need structure. These trends may reorganise the supply chain networks in national and regional levels.

18. General public may develop some positive altitudes over the special duties performed by various essential services in society, especially, health workers, social workers, police and armed forces who are involved in quarantine processes, etc. However, there should be very efficient supply chains to maintain these services in optimum operation when necessary to society, particularly, in South Asia.

19. Reduction in plastic and polythene use at the domestic level, thus reducing the environmental pollution. As a whole, it may contribute to global environmental protection efforts. Especially, it may temporarily reduce greenhouse gases due to the minimum use of vehicles and industries in the world. Perhaps, there may be some climate changes in the environment.

20. Reduction in the environmental pollution in the world, regional and national contexts. Mainly, air, sound, and water pollution will be reduced. There are some studies conducted, and they reveal that the pollution level is reduced drastically in all these three sectors.

21. Possible formation of further philanthropic ideas amongst the upper hierarchy segments in society. Thus, the domestic supply chain networks should capture these demands effectively.

22. If the government is successful in managing the COVID-19 instead of developing a pandemic situation, it can lead to a stable political order in society. Perhaps, the incumbent government could win another term in power as the pandemic situation has provided a great opportunity to compare each country and its skills in the governance of their political regimes.

23. Reduction in crimes such as drug addiction, alcoholism, gambling, prostitution or commercial sex, violence and suicide. Again, the supply chain networks in commercial sex, illicit drugs, etc. may change.

24. Some countries may amend or introduce specific legislation based on their experiences in the management of COVID-19 pandemic situations. Particularly, trading pacts amongst regional countries may change whilst new pacts may also be formulated.

25. Some countries may review policy gaps and take action for policy updates. Sri Lanka needs a policy on indigenous medicine (traditional medicine) which is not covered by the existing health policy in Sri Lanka. It is the right time to respond to the court decision and request a new pharmacopeia with a list of codes.

26. More utilisation of the internet for sharing ideas, new knowledge, filtering knowledge gaps, news messages, etc. This may open up more avenues to reduce the stress level of the people.

27. Return migrants who are having strong financial resources may invest in Sri Lanka if the socio-economic and political stability established after complete control and management of COVID-19 in Sri Lanka.

28. Returning migrants with less or poor financial resources may seek jobs in the apparel sector or plantation sector. Therefore, there will be a high supply in the labour market 
in the country. This situation may impact the new formation of production and supply chain networks.

29. There will be more research on COVID-19, particularly discovering a vaccine and medical strategies which are more effective in patient management. If any new vaccinations are discovered, there will be a massive demand from each country and new supply chain networks will emerge within the health sector.

Therefore, positive impacts are relatively high and some impacts are short term and most others are long term. This situation depends on the early stage of April 2020 and the shape could change due to several global socio-economic and political factors. So far, COVID-19 is in a rapid spread tendency in most countries, and there are no sufficient health and socioeconomic facilities, especially supply chain networks to address the need structure of the pandemic situation in these countries. When the Indian scenario is analysed, the COVID19 impacts will be the most painful here when compared to other countries. The social system prevailing in India is not simple in terms of managing the pandemic situation. It is very clear that any society which has a high social disparity may have to face the most negative impacts.

The negative impacts towards the family, communities, nations, regions and the world push them backward in any sector or socio-economic and political spheres. Several elements which cause negative impacts can be identified as illnesses or COVID-19, pandemic situation, deaths, social distancing, curfew and the lock-down of the entire functional mechanism of a single society and the global network in production, trade, supply chain networks, transportation, social networking and political network. Therefore, this paper has given similar attention to the negative impacts of COVID-19 at the local, regional and global contexts based on the situation in early April 2020. They are given in the following:

1. The pandemic situation has spread as a global pandemic disease which is creating fear, stress, stigma, minimising social networks, etc.

2. Health and medical systems, especially biomedical systems, have taken their maximum effort but the healthcare system itself is affected due to various conditions in nature. Thus, there are many deaths reported though the biomedical system has made an enormous effort.

3. High rate of deaths due to various illnesses or complications of diseases occurring amongst the patients, especially the elderly who are affected by COVID-19.

4. Impossible tasks and challenges to the medical staff, supporting staff, social workers and health administrators at local, domestic and/or global levels. The World Health Organisation (WHO) is the primary entity followed by other United Nations (UN) agencies which are responsible during a regional and/or global pandemic situation.

5. Some countries such as Italy, Spain, USA and China and a few other European countries are facing a much higher disintegration in all subsystems of society. Thus, the social system needs a complete reorganisation and integration to survive.

6. Dismantling the family relationship and intimate relationships with relatives, neighbours, various communities, etc. These conditions may lead to interpersonal conflicts and domestic violence in the family.

7. Losing the knowledge, experience, and services of the elderly would mean that the next generation would not be able to share them for their betterment.

8. Downward trends of family economic conditions and several lower hierarchy social classes facing unbearable economic hardships due to lack of daily or monthly earn- 
ings. Though there are market accessibility and supply chain network even under the limitation of social mobility, they do not possess the purchasing power.

9. Disruptions of schools, universities and vocational education segments where they have to seek certain optional strategies to cover up their educational goals. Especially, they may face some irreversible gaps in their education. All supply chain networks in the education field have been interrupted.

10. Some people may face various kinds of stress, social stigma and depression conditions due to the malfunction of the social system.

11. Possible social conflicts or conflicts of interests in the subsystems and this may lead towards the social system. Some institutions and organisations may not possess sufficient capacities to find remedial solutions to fill the gaps and issues.

12. Decline in religious belief systems and practices in all religions and people may not believe in superstitious powers, in god and other divine and invisible elements in society.

13. If the government and its subordinate authorities face some inadequate workable decisions or binding decisions and poor policy applications, it may lead to political instability in society. These conflicts of interests may cause political changes in society.

14. Social unrest, stress and social stigma amongst the family members due to their detachment from family as a result of local and international migration. This may get aggravated further through the suspension of continental air transportation under lock-down situations.

15. Disruptions in the productions of primary and secondary items in the society. Especially, issues in the production of primary items may lead to social unrest in society. Less demand and lack of proper supply chain networks may aggravate the existing unrest level.

16. There are many people who are losing their jobs and incomes in the formal and informal sectors in the society.

17. Service providers' (supply chain networks) inability to continue the day-to-day supply of commodities and other services due to the lack of profit margins. It may lead to detachments from such entities or services, and some people may find alternative solutions. Thus, there may be some temporal decline in supply chains in society.

18. People might depend on rumours and other informal channels of information if there is a chaotic condition in formation channels or the dissemination of information. Especially, if there are some loop halls in supply chain networks, these rumours may work rapidly with different social and economic impacts.

19. Certain social classes may display their egoistic ideologies at the time of accumulating primary or essential goods and services. This may cause some negative attitudes amongst other social classes by creating conflict of interests.

20. Global economic recession and increase in poverty level in society. This may lead to financial crises such as a decline in monetary values, share market values and businesses, changes in supply chain networks, and purchasing power of the people.

21. The country has to take alternative action to maintain a stable economy. The developing countries and poor countries may get more loans and grants for their economy to survive. Thus, there will be more economic and political dependency in these countries. As a result of this condition, countries in the hegemonic circle may directly or indirectly fulfil their hidden agendas in the territories of such dependent countries. Being South Asian countries, there are certain common social and economic characteristics that need to be safeguarded during the pandemic situation. 
22. The pandemic situation will directly influence the Sustainable Development Goals (SDGs) defined to be achieved by 2030, since some countries may not allocate financial resources to meet the country-specific targets.

23. Internal fragmentation may occur in global hegemonic countries, particularly in the USA and they may attempt to regain the hegemonic power through various economic and political strategies. Perhaps, they may go for direct war strategies with other countries or accelerate existing intervention in the Middle-East region.

24. Sri Lankans who have been employed in foreign countries may return home and future foreign revenues may reduce. It is one of the major revenue in Sri Lanka, especially the migrant workers in the Middle-East, Europe and East Asian countries made a significant contribution to the Sri Lankan economy. This may cause some effects in supply chain networks in Sri Lanka as well as South Asian countries.

25. If the government of Sri Lanka does not engage the returning migrants fruitfully, they may get frustrated and thus cause some vulnerability in the informal sectors of society.

When these positive and negative impacts are considered, it is very clear that COVID19 has caused more positive impacts to the nations, regions and the world, particularly to South Asian countries. However, some countries such as Italy, Spain, the USA, and China and several European countries have suffered a lot. At the time of writing this article, COVID-19 has infected 5,306,928 persons worldwide (when the article was finalised for publication, the number has increased up to 15,947,291). Comparatively, these positive and negative impacts are valid for these countries too, irrespectively of the level of the spread of COVID-19.

The proposed future action plan or COVID-19 recovery action plan mainly focuses on the socio-economic, environment and political spheres and not on the medical and technical spheres. Table 1 illustrates this categorically.

When these different domains or spheres are looked at, it becomes very clear that there are higher numbers of actions identified under social domains. It implies that COVID-19 is a pandemic situation and it has more critical aspects in the social domain which needs to be looked at through a sociological rather than administrative or political perspective. Furthermore, all responsible officers as well as the public could provide at least a minimum input than all actions highlighted in Table 1. Moreover, most of the proposed actions are focused on short-term and medium-term actions. However, there are some significant actions identified under long-term actions which are related to individual and group level attitudes.

All these analyses done and elaborated in different subsections of the paper highlight that there is a pivotal role to be played by the supply chain networks and management clusters in every society. In South Asian countries, the situation in supply chain networks and management is more specific than in other parts of the world because all these countries maintain a dual mode of economy-subsistence and commercial. Particularly, end users and consumers are engaged in some domestic or cottage production systems. If they have a surplus, then they share it with their relatives and neighbours as a cultural habit. Thus, they are not totally dependent on the market system. Some of them sell these domestic products to boutiques. Sometimes they give some value addition as cottage products and try to sustain a stable supply chain network. This situation is seen in many South Asian countries. Therefore, sustainability in supply chain networks in South Asian countries is highly volatile. However, it is obvious that the supply chain networks are influential and of paramount importance under the COVID 19 pandemic situation in South Asian countries. 


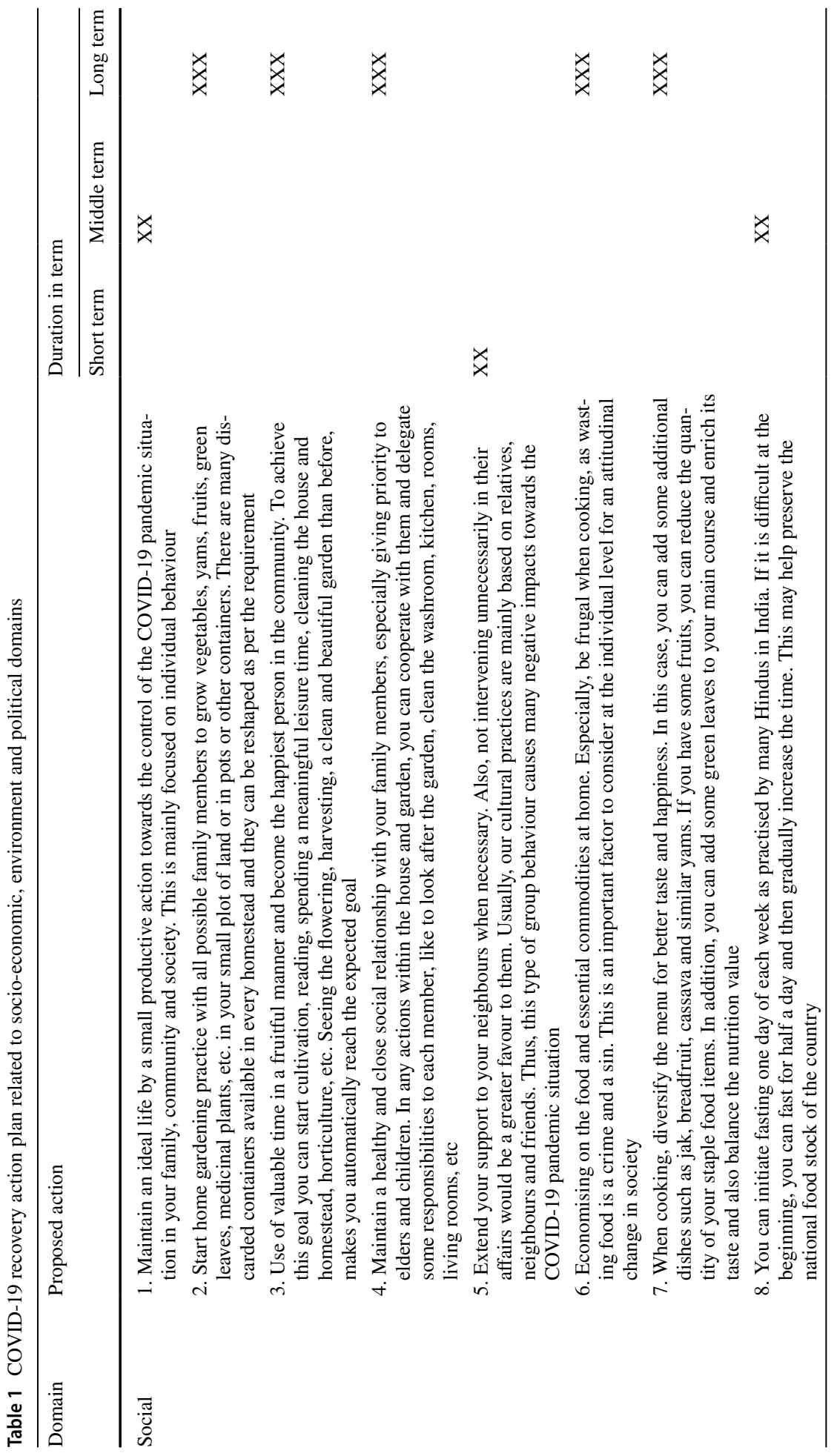




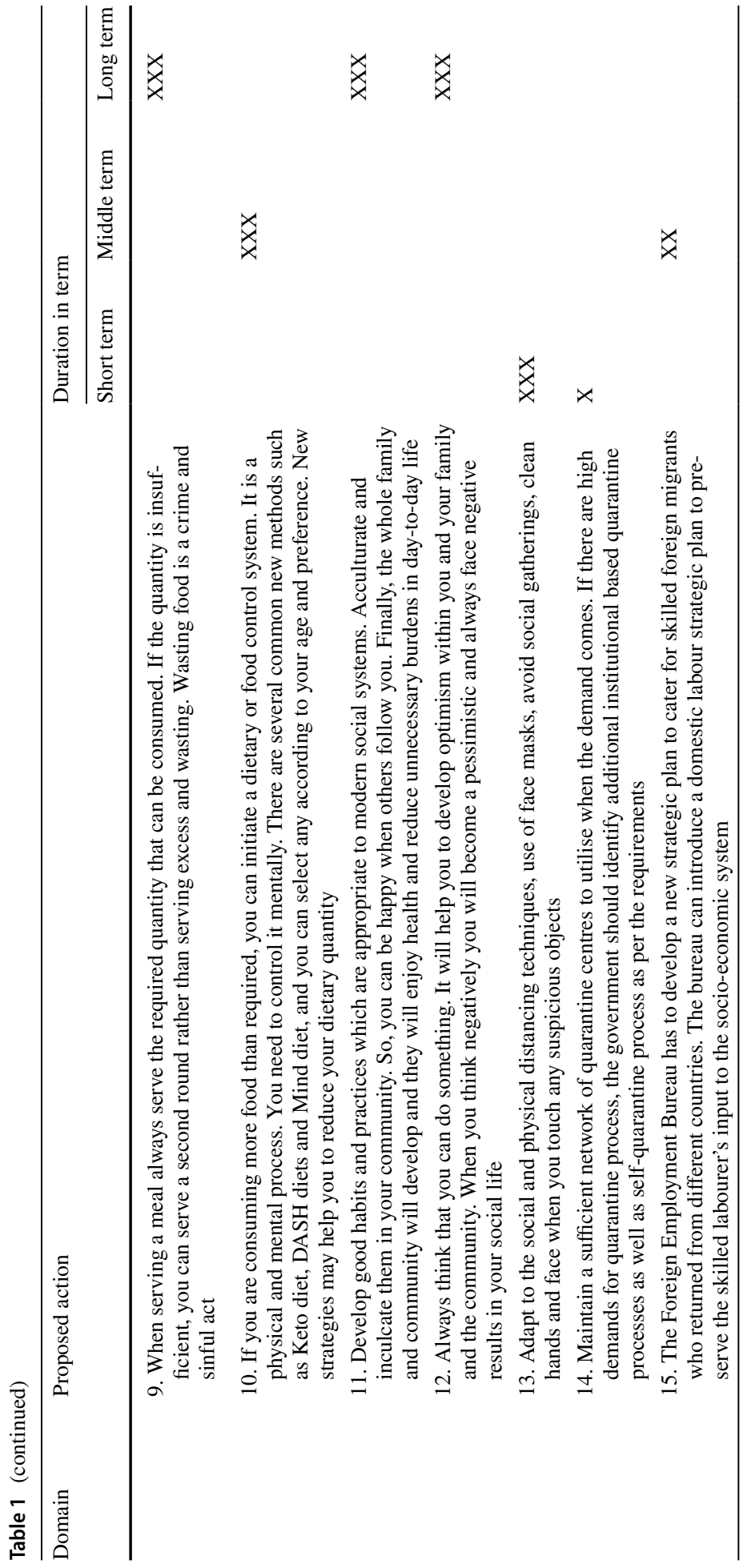




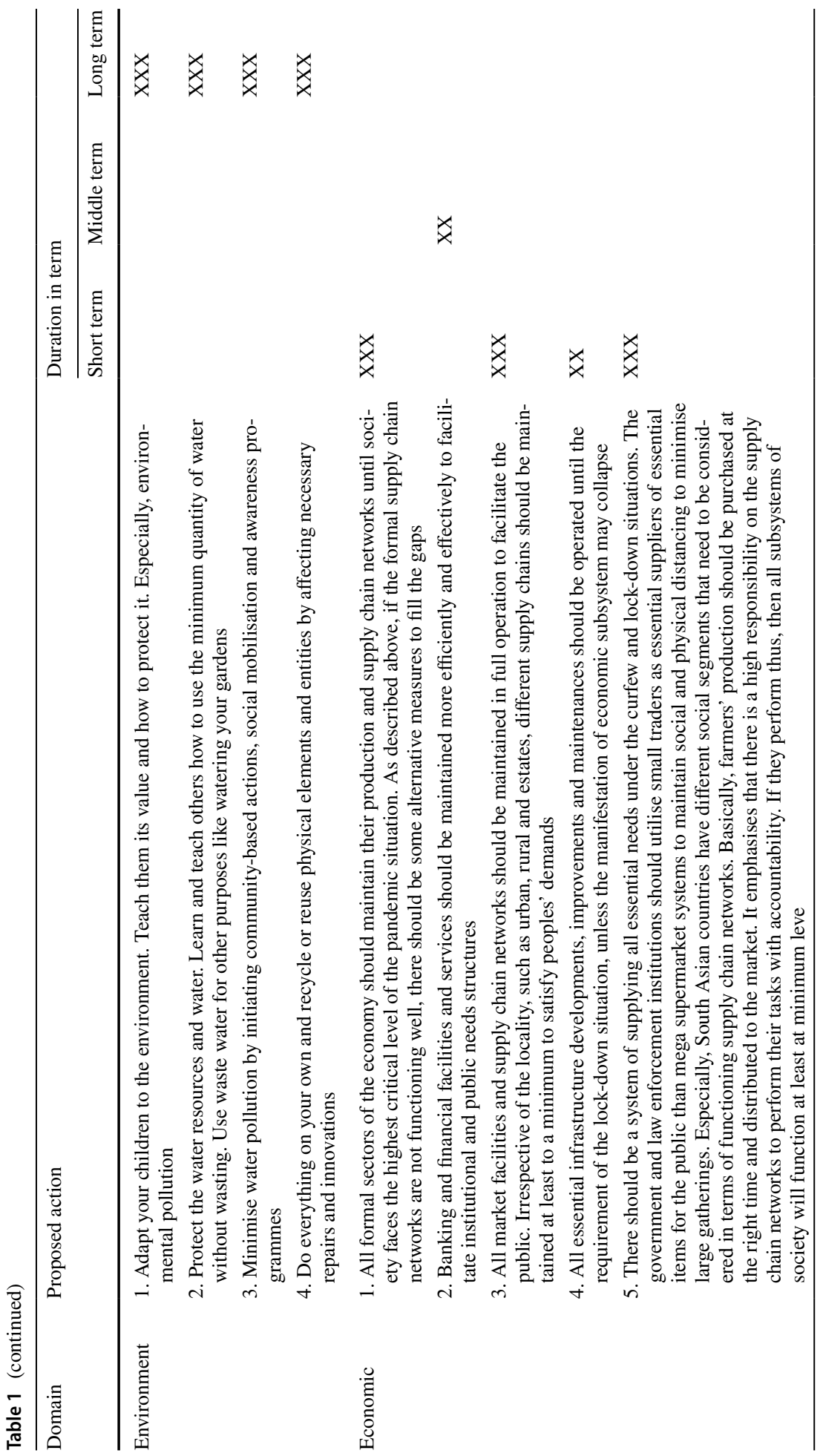




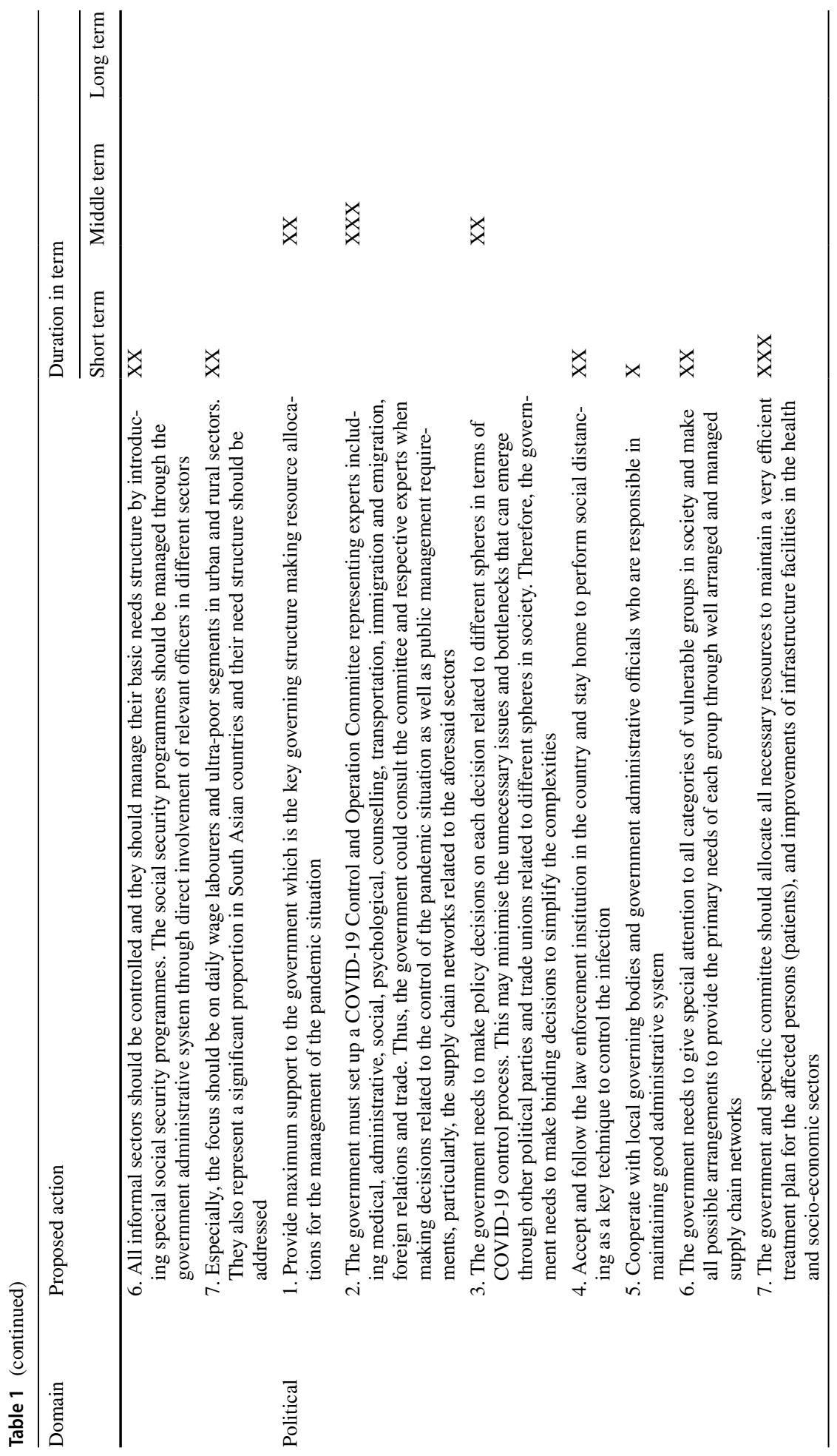




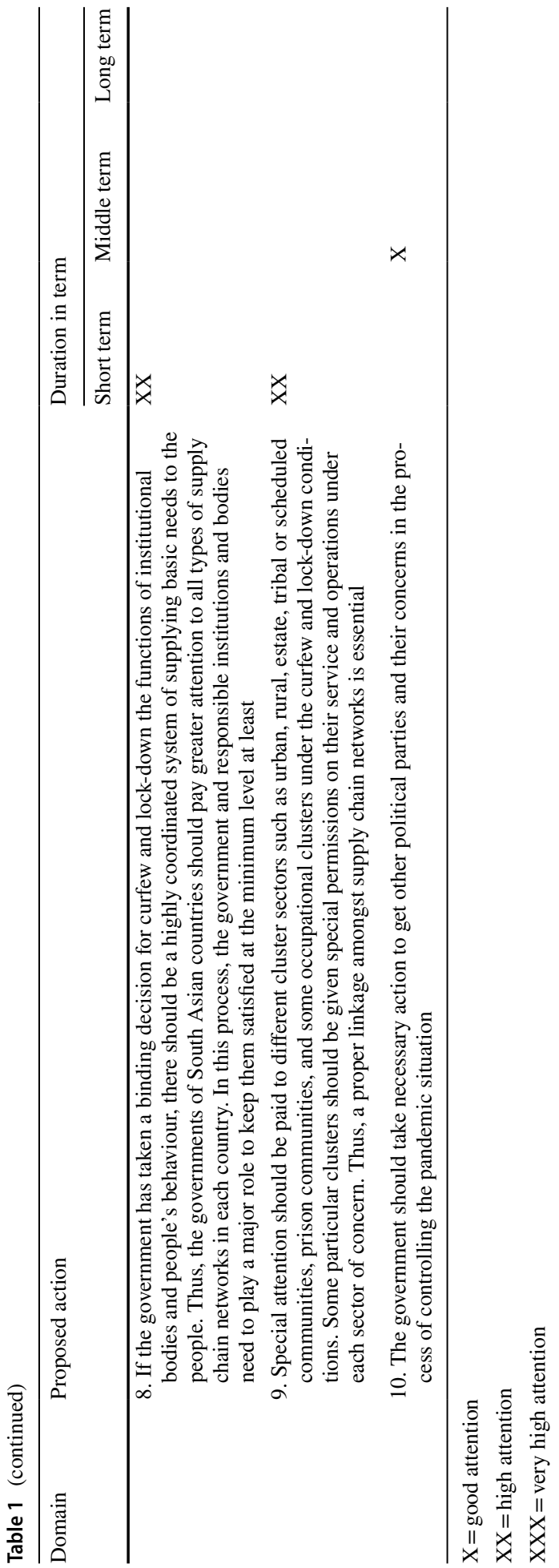


Especially, if the authorities focus on this COVID 19 recovery action plan, it will help protect the family, environment and the nation. Therefore, we need to have an attitudinal change towards a more sustainable control of the pandemic situation in our country. The entire analysis of this paper is mainly based on the researcher's Sri Lankan and other South Asian countries' experience, particularly in development planning. The insight will help to manage and control the COVID-19 pandemic situation in South Asian countries. If we are able to adapt to the situation as explained, this approach will help us to maintain a stable and sustainable development programme for these countries, particularly for Sri Lanka.

When compared to several historical experiences in managing pandemic situations, this COVID-19 pandemic situation can be used as a development opportunity to enjoy a much higher take-off with a new set of attitudes in the process of development.

\section{References}

Knudsen M (2010) Surprised by method-functional method and systems theory. Forum Qual Soc Res Open Access J 11(3), Art. 12. http://www.qualitative-research.net/index.php/fqs/article/view/1556/3067

Luhmann N (1995) Social systems. Stanford University Press, Stanford

Malpass D (2020) Remarks to the Development Committee. https://www.worldbank.org/en/news/state ment/2020/04/17/world-bank-group-president-malpass-remarks-to-the-development-committee

Parsons T (1951a) The social system. Free Press, New York

Parsons T (1951b) Toward a general theory of action. In: Shils EA (ed). Harvard University Press, Cambridge

Rocher G (1972) Talcott parsons and American sociology. Thomas Nelson and Sons Ltd., London

World Bank (2020a) https://www.worldbank.org/en/news/press-release/2020/04/12/south-asia-must-actnow-to-lessen-covid-19-health-impacts

World Bank (2020b) https://www.worldbank.org/en/country/srilanka/overview

World Bank (2020c) https://www.worldbank.org/en/news/press-release/2020/03/30/east-asia-and-pacificcountries-must-act-now-to-mitigate-economic-shock-of-covid-19

Worldometers.info (2020) https://www.worldometers.info/coronavirus/\#countries

Publisher's Note Springer Nature remains neutral with regard to jurisdictional claims in published maps and institutional affiliations.

K. Karunathilake is attached to the Department of Sociology, University of Kelaniya, Sri Lanka. He is the Cadre Chair Professor in Sociology and he has vast experience in social impact assessment, social evaluations, social development and resettlement. He works as a freelance consultant for the Asian Development Bank, World Bank, UN Agencies and other similar organisations. He gained his doctorate from Centre for Study Social Systems, School of Social Sciences, Jawaharlal Nehru University, New Delhi in India. 